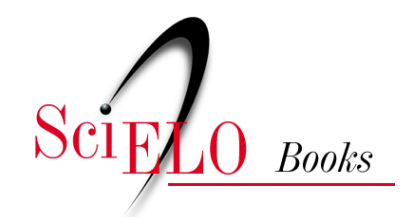

\title{
II. Sociabilidade e conflito no Rio de Janeiro joanino
}

\author{
Juliana Gesuelli Meirelles
}

\section{SciELO Books / SciELO Livros / SciELO Libros}

MEIRELLES, J.G. Sociabilidade e conflito no Rio de Janeiro joanino. In: A família real no Brasil: política e cotidiano (1808-1821) [online]. São Bernardo do Campo: Editora UFABC, 2015, pp. 35-42. ISBN: 978-85-68576-96-0. https://doi.org/10.7476/9788568576960.0003.

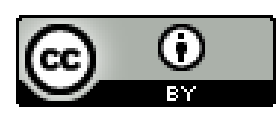

All the contents of this work, except where otherwise noted, is licensed under a Creative Commons Attribution 4.0 International license.

Todo o conteúdo deste trabalho, exceto quando houver ressalva, é publicado sob a licença Creative Commons Atribição $\underline{4.0}$.

Todo el contenido de esta obra, excepto donde se indique lo contrario, está bajo licencia de la licencia $\underline{\text { Creative Commons }}$ $\underline{\text { Reconocimento 4.0. }}$. 
II.

SOCIABILIDADE E CONFLITO NO RiO DE JANEIRO JOANINO

A nova sociabilidade vigente na Corte, assim como os conflitos decorridos dessas transformações na organização do espaço público, aparecia nos múltiplos universos dos atores sociais. Das novas práticas alimentares às múltiplas formas do convívio entre o universo escravo e a sociedade de corte que se formava nos trópicos as mudanças são visíveis.

\section{A ALIMENTAÇÃo E A SOCIABILIDAdE COTIDIANA À MESA}

Durante todo o período em que a corte esteve por nossas terras, a alimentação foi uma temática de muita relevância para a população da cidade do Rio de Janeiro. Nos anúncios publicados na Gazeta encontramos uma variedade enorme de venda de alimentos: fosse os importados da Europa ou aqueles produzidos no Brasil, o fato é que, com a ampliação do universo culinário, surgiam novos hábitos culturais que delinearam, ao longo dos anos, novas formas de sociabilidade à mesa.

Preços de Mercadorias no Rio, início do Século XIX

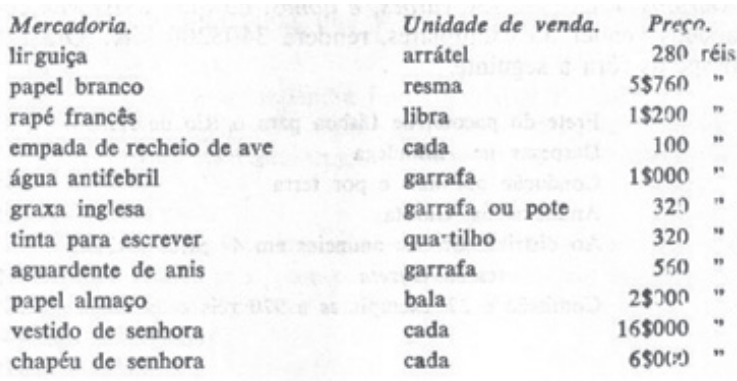

(Fonte: SILVA, Maria Beatriz Nizza da. Livro e Sociedade no Rio de Janeiro (1808-1821). Separata da Revista de História, n. ${ }^{\circ} 94$, São Paulo, 1973.)

Em 18 de dezembro de 1813, por exemplo, eram publicados no jornal os diversos produtos alimentícios que podiam ser encontrados na loja de Luís Zoveti e Cia., na rua do Ouvidor, n. 9. Mostarda, conservas inglesas ditas 
de "qualidade", molhos para peixe, azeite engarrafado vindo de Florença, diferentes vinhos estrangeiros, frutas em aguardente, chás, doces e chocolates eram gêneros anunciados pelo proprietário do estabelecimento. A venda de produtos exóticos também já fazia parte do cotidiano da população. Em novembro de 1814, a Gazeta anunciava a venda de tâmara, fruta até então desconhecida no Brasil e que tinha grande estima nas mesas de sobremesas europeias.

O contato cada vez maior com a cultura europeia também estimulava um novo hábito na Corte: difundia-se o costume de almoçar fora de casa, nas denominadas casas de pasto, que serviam diariamente diferentes cardápios pré-estabelecidos com preços também já previamente fixados pelo comerciante. Tais mudanças na prática incentivam a procura por cozinheiros, um ofício bem remunerado. Em 1808, "um cozinheiro que soubesse trabalhar de caçarolas e massas ganharia por mês $14 \$ 000$ réis, mais do que muitos letrados obtinham em suas aulas", elucida a historiadora Maria Beatriz Nizza da Silva (2007: 35). A sobremesa teve seu espaço garantido. Em julho de 1813, Vicente Ferreira, o ilustre chocolateiro da princesa Carlota Joaquina, abria uma fábrica de chocolate na rua do Ouvidor, n. 28. Para além da venda de todas as qualidades de chocolate, a loja vendia ainda extratos de manteiga de cacau para a produção de outros doces (Gazeta do Rio de Janeiro, 1813, $\mathrm{N}^{\circ}$ 58). A diversidade e a quantidade dos gêneros que foram importados nos Reinos de Portugal e Brasil durante 1816 foram tema de destaque da folha oficial, tamanha era a preponderância do comércio interatlântico de alimentos dentro dos limites do Império Português.

"O comércio ambulante, estimulado pelas feiras livres e as negras quitandeiras, aparecia como modo de abastecimento fundamental nesse período, permitindo enxergar outros alimentos que compunham um rico cenário alimentar (...) Tratava-se, de certa forma, de uma alimentação baseada em tudo o que a terra podia oferecer, embora já adaptada e reelaborada de acordo com os diversos paladares que por ali conviviam", analisa a antropóloga Paula Pinto e Silva (2008: 6). As transformações na vida cotidiana da Corte chegavam para ficar. 
Resumo de todos os effeitos, que no decurso do anno passalo for $\bar{a} 0$ importados dos Reinos de Portugal, do Brazil, $e$ das suas dependencias, no de Hamburgo.

Assucar 17:028 caixas, 109 fechos, 141 batrís, 22 sacas.

Agoardente de cana $3 \mathbf{1}$ pipas, 10 barrís.

Algodāo 1:14t fardos, 2310 sacas. - Dito fabricado 39 volumes.

Amendoas 4 barrís.

Arroz 5 barris, 2:747 sacas.

Anil 16 caizas.
Azeite 3 barrís, 4 caixas com dito enfrascado, I jarro.

Azongue 550 frascos.

Baga 122 sacas.

Balsamo 32 barris. - Dito de Copaiva 6t barrís.

Borra de vinbo 6 barrís.

Cacdo r: 273 sacas.

Caffe 2:580 ditas, 25 fardos.

Canella 4 caixas, $t$ dito.

Casca de lananja 16 ditas, 13 sacas.

Cassia lignea 81 caixas.

Cebollas $4 \mathrm{I}$ cestos.

Cerdas de cavallo 43 fardos.

Cod 3:18t caixas inteiras, meias, a quartas.

Chocolate 7 ditas.

Cobre 287 barris.

Cortiçd 528 quintaes.

Couros 31:377.

Curcuma 29 sacas.

Doces 12 caixis.

Drogaria 22 barris, 6 fatdos, 14 volumes.

Figos passados 40 barrís, 100 ceiras, 300 arrobas. Fulbas de loturo 135 fardos, 767 sacas.

Frata 7078 caixas, 909 meias ditas.

Gengibre 300 sacas.

Gommas 18 barrís, 27 sacas.

Dita elastica 12 ditos, 37 ditas.

Jpecacuanba 1 barril.

bï 6 bilóes:

Licores 43 caixas .com frascos.

Lixa 2 fardos.

Toucta 1 caixa.

Melaço 8 bartis.

Pato amarello 2:200 arrobas, P. m. of m.

Dito Brazil 1:108 trancas.

Dito campecbe huma partida.

Ditonebano if francas.

Pacs diversos de timura $4: 090$ trancas.

Passas 500 caixinhas.

Rimienta 15 fardos, 35 sacas.

Pontas de boi $321: 762$, e 2 partidas. - 6:200 chapas. Pontinhas dito $15: 942$, 50 batris,

Rolbas 8 fardos.

Sal 288 moios, e I partida.

Salsa pitrilba 4 : fardos, 9 sacas.

Sassafraz; 1 partida.

Sebo 80 barris, 110 marquetas.

Tabaco 133 ditos, 5:590 balóes, 776 fardos, e 4:564 rolos.

Dito em pó a caixa.'

Tapioca 135 barris, 700 sacas.

Evas 20 caix 15,6 meias dias, 35 jarros.

Vinbo $17^{8}$ pipas, 170 meias, 111 quartolas, 11 caixas com dito engarrafado, 37 barris vátios.

$V a r i a s$ fazendas e effeitos: anonimos 14 caixas, 16 barrís, 1 fardo, 11 sacas, 4 volumes.

(Fonte: Gazeta do Rio de Janeiro, 19 de julho de 1817, n.58.) 
Paralelamente à formação desses espaços culturais que garantiam um novo locus de sociabilidade, o cotidiano da Corte também era marcado por tensões e conflitos sociais que permeavam a vida dos escravos, que viviam a complexa realidade de habitarem na cidade sob a escravidão urbana.

Ser escravo ou escrava nos centros urbanos do Brasil no raiar do século XIX significava viver sob a forma de ganho, prática que lhes conferiam uma importante - mas relativa - mobilidade pela cidade. $\mathrm{O}$ trabalho sob a condição de ganho era exercido cotidianamente e não tinha a interferência explícita do senhor: este recebia ao final do dia ou do tempo fixado a quantia por ele previamente estabelecida.

No dia a dia, ao disporem provisoriamente de sua força de trabalho, os escravos desempenhavam diversas funções, tais como ama de leite, jornaleiro, sapateiro, doceiro, padeiro, cozinheiro, vendedor ambulante, marceneiro, carpinteiro etc., que eram comumente comercializadas na cidade por aqueles que detinham o seu pátrio poder. Não raro, os proprietários descreviam as "qualidades" de seus escravos quando desejavam vendê-los rapidamente. Em 1813, por exemplo, era anunciada a venda de um cativo dito bom barqueiro e canoeiro com amplas habilidades para marinheiro, que não continha vícios, defeitos físicos ou doenças (Gazeta do Rio de Janeiro, 1813, $\mathrm{N}^{\circ} 27$ ). Escravas cozinheiras, engomadeiras, costureiras e amas de leite também adquiriam grande valor no mercado, já que tinham todos os dotes necessários para realizarem o bom serviço de uma casa (Gazeta do Rio de Janeiro, 1820, $\mathrm{N}^{\circ} 60$ ). Mas independente de praticarem um trabalho especializado, os escravos urbanos - na maioria das vezes - passavam o dia longe das vistas do senhor. "[Essa situação lhes] permitia também um maior contato com os demais grupos da sociedade, o que lhes facilitava estarem continuamente informados sobre os acontecimentos e às vezes conhecerem alguns de seus poucos direitos", elucida a historiadora Leila Mezan Algranti (1988: 20).

$\mathrm{O}$ amplo contato desses cativos com a população livre era um fator de grande temor social. A constante ameaça de rebelião contra o sistema escravista amedrontava os demais grupos sociais que concebiam os negros - cativos ou libertos - como suspeitos ou criminosos em potencial. Apesar do alto policiamento, uma gama enorme de atentados à ordem pública era comumente praticada na cidade. A maioria das ocorrências como os roubos, crimes e assassinatos recaíam sobre os escravos, que não tinham a quem apelar. Ao contrário, tinham seus passos vigiados pelos juízes de crime dos bairros que informavam Paulo Fernandes Viana sobre os "distúrbios" cotidianos. 
Fugas e revoltas coletivas organizadas era uma realidade que deveria ser denunciada a fim de melhor vigiar, controlar e punir esses sujeitos. Diante desse cenário, muitos proprietários publicavam anúncios na Gazeta do Rio de Janeiro com o intuito de reaver "a perda de seus bens"; atitude que conferia ainda mais visibilidade à situação desses escravos.

Em fevereiro de 1817, saía publicado na Gazeta um anúncio sobre a fuga de uma preta de nome Manoela. A narrativa detalhava não só a data da fuga da escrava (20 de outubro de 1816), como também a descrevia por completo: vinda de Moçambique, Manoela contava com 14 anos de idade, tinha feições bonitas, delgadas de corpo, braços longos, pé comprido (sic) e dentes limados. A vestimenta da escrava no dia da fuga foi vivamente rememorada: sumira de vestido branco, com roupinhas de folhos. Àquele que achasse a escrava, José Rodrigues do Orte, seu proprietário, prometia boas recompensas (Gazeta do Rio de Janeiro, 1817, $\mathrm{N}^{\circ} 13$ ).

Três anos depois, em 1820, o desaparecimento de cinco escravos de Moçambique e do Congo, que trabalhavam na fazenda de Santo Antonio, na freguesia de Jacutinga, também foi motivo para a publicação de um anúncio na Gazeta. O texto denunciava a estratégia da fuga que parecia ter sido previamente planejada: os cativos vestiam carapuças encarnadas e mantas brancas de algodão de Minas, o que supostamente os identificariam como fujões. O proprietário garantia boas gratificações para quem deles dessem notícia ou os conduzisse à fazenda (Gazeta do Rio de Janeiro, 1820, $\mathrm{N}^{\circ} 80$ ).

Outro viés muito presente no cotidiano escravista da Corte foi a capoeira, uma prática de defesa e ataque trazidos pelos africanos ao Brasil que muito incomodava a sociedade cortesã carioca. Designada na época como jogo, a capoeira era composta por rápidos movimentos em que o capoeira golpeava seu adversário com a cabeça ou com as pernas. As mãos serviam para o apoio no chão quando o "jogador" atirava os pés na direção do antagonista, atingindo-o em cheio. Foram tantas as inconveniências causadas pelos capoeiras que d. Pedro, em 6 de fevereiro de 1822, escreveu do próprio punho uma carta ao brigadeiro Carlos Frederico Bernardo de Caula. Ao mesmo tempo em que o documento exigia medidas enérgicas e violentas contra os capoeiras, também cedia vantagens aos soldados que conseguissem prender os cativos que estivessem capoeirando.

Meu Caula,

Mande passar uma portaria ao Comandante da Guarda da Polícia em que se lhe estranhe muito da minha parte, o pouco cuidado que tem tomado, em prevenir as capoeiragens pelas ruas que tem chegado a ponto de quebrarem vidros das janelas e na mesma Portaria autoriza-lo para que logo se agarre qualquer capoeira que seja escravo na ação de capoeirar seja logo conduzido 
imediatamente ao moirão mais próximo, e aí surrado com 100 açoites, e depois entregue ao Senhor se na tiver feito mais nada que capoeirar, e na mesma ordenar ao comandante que todo o soldado que apanhar um capoeira terá quatro dias de licença, e assim na proporção de quantos agarrarem capoeirando.

Deste seu amo e amigo

Pedro (apud Prado, 1968: 254).

Geralmente, a habilidade e a rapidez dos golpes era motivo de grande apreensão por parte dos policiais que, na maioria das vezes, tinham dificuldade de se defenderem, o que causava muita correria e grandes tumultos na cidade. A notícia que correu pela cidade em 2 de abril de 1814 mostrava com exatidão a amplitude desses conflitos vividos no cotidiano das ruas. A Intendência Geral da Polícia tornava público que no Calabouço (prisão da cidade) havia 34 escravos fugidos que tinham sido achados em quilombos ou mesmo fora deles. A lista publicada na secretaria da intendência informava aos senhores que a partir daquela data já podiam ir verificar se eram identicamente os próprios, para os receberem no prazo de três meses. Destacava, ainda, que os escravos que não tivessem seus donos apresentados seriam entregues ao Magistrado, responsável por arrecadar "os bens", vendendo-os, sendo que o produto líquido das despesas deveria ser entregue para os cofres do fisco (Gazeta do Rio de Janeiro, 1814, $\mathrm{N}^{\circ} 27$ ). Ao cultivarem essas práticas e códigos culturais intrínsecos ao universo escravo, muitos cativos eram violentamente reprimidos, o que, por fim, era um motivo a mais de aprofundamento dos conflitos intrínsecos ao sistema escravista.

O universo feminino também sofreu muitas transformações durante o período joanino. Com o estabelecimento da corte, uma ampla gama de novidades passou a fazer parte da vida cotidiana das mulheres: dos livros publicados pela Impressão Régia ao oferecimento de trabalho doméstico, houve um grande incremento nas ofertas de diversos produtos importados vindos da Europa e nas oportunidades de aprimoramento cultural.

Vendas de novelas com enfoque moral como O bom marido, $A$ boa mãe, A má mãe, Duas desafortunadas, Triste efeito de uma infelicidade, Amor ultrajado, Castigo da Prostituição, Infelicidade vingada, As mulheres célebres da Revolução, ou Quadro enérgico das almas sensiveis etc. eram títulos geralmente anunciados na seção de Avisos da Gazeta (Gazeta do Rio de Janeiro, 1817, $\mathrm{N}^{\circ}{ }_{17}$ ). Além de livros com temas femininos, o anúncio de joias, roupas e utensílios de origem francesa e inglesa recheava as páginas da folha. Em 1817, o comerciante Joaquim Martins Pinto, residente na rua Direita, anunciava a chegada de vestidos de seda de todas as cores, lavrados de ouro, prata e matiz. Cambraias bordadas, ornamentos para cabeça, muitos xales de lãs e 
gargantilhas, eram todos ornamentos chegados da França (Gazeta do Rio de Janeiro, 1817, $\mathrm{N}^{\circ} 85$ ). Quanto à oferta de emprego, muitas mulheres livres eram procuradas para o trabalho doméstico. Em 1820, Antonio Ferreira da Rocha procurava uma governanta branca ou parda com reconhecida capacidade doméstica para tratar do asseio da casa onde habitavam um homem viúvo e seus três filhos (Gazeta do Rio de Janeiro, 1820, $\mathrm{N}^{\circ} 25$ ).

A chegada de mulheres estrangeiras também se tornava uma realidade. Por aqui afluíram as senhoras da nobreza portuguesa, as esposas e filhas dos viajantes, as atrizes que vinham encenar peças de teatro e óperas no Real Teatro, assim como as profissionais liberais. Em maio de 1820, a modista inglesa Hannah Hairris, que tinha sua loja na rua do Ouvidor n. 17, anunciava a "preços cômodos" o recebimento de diversos objetos femininos vindos de Londres e Paris. Entre aqueles considerados de maior apreço, destacava os chapéus pretos de palha inglesa, vestidos bordados de filó de ouro e prata, e rendas de ouro e prata e pérolas (Gazeta do Rio de Janeiro, 1820, $\mathrm{N}^{\circ} 39$ ).

A multiplicidade de códigos e costumes culturais tão singulares aparecia de diversas formas no cotidiano do universo feminino. O papel das mulheres pertencentes às altas camadas da sociedade se restringia ao universo privado da casa. Como provedora dos alimentos da família, ficava também no comando da escravaria, além de ter em suas mãos a supervisão da educação de seus filhos. Quanto aos hábitos mais comuns, se ocupavam dos trabalhos manuais: bordar, fiar, costurar e tecer sempre foram atividades altamente indicadas às mulheres tanto pelos moralistas como por aqueles que se preocupavam com a educação feminina. Nesse período, havia a concepção de que a prática do uso das mãos femininas era uma forma eficaz de se evitar a ociosidade e, por consequência, os maus pensamentos e ações, razão pela qual elas raramente saíam de casa desacompanhadas de seus maridos ou escravos (Algranti, 1997: 122). Quando saíam, geralmente era para cumprir um importante ritual religioso: assistiam à missa, que ocorria às 4 horas da manhã.

Por outro lado, a valorização da educação feminina em outros espaços que não fosse o ambiente doméstico começava a ganhar terreno na cidade, inclusive pelas mãos de senhoras distintas da sociedade. O caso de D. Catarina Jacob é emblemático: em dezembro de 1812, a senhora informava ao público a abertura de uma academia para instrução de meninas que privilegiava justamente o ensino dos bons manejos das mãos e o cuidado com a casa. $\mathrm{O}$ aprendizado das Artes como a dança e a música seriam pagos à parte. 


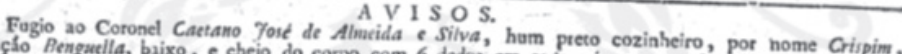

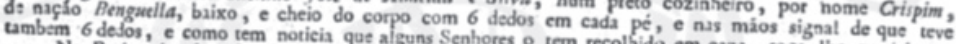

Na Botica de Antonio Joaguin de siva Genhores o tem recolhido em caza, foza lio participem.

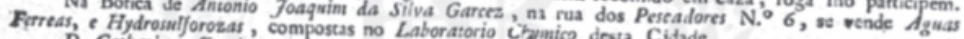

D. Cabarina Tarob toma libendade

Academia para instrucçáo de Meaiass na rua de fazet sciente ao Publico, que ella tem estabelecido huma a let, escrever, e fallar as lingus Portugueza da Lapa, defronte da Ex. ina Duqueza, em que ensinuri bordar, e o manjo da Caza. Esta esperancada que, $\mathrm{cm}$ conseguenciasts ; toda a qualidade de costura e eiçá, Religia, e Moral, mereceri eternamente que, em consegnencia do seu cuidado, e atvençio na edafiarem esta honta : cada Menina cópo de prata, pagario por ead tráa a cana compteta, tres toalhas de máos, hum talher completo, e msate todas as pessoss, quz cada Menina dezoito mil rtis por mez, sendo a quarteis adiantados. Igule go á parte; mandario todos os Sabhados os stus Meninis aprendio Muziea, Dança, e Desenho, serí pa. mudança, fizulmente as peisoas quequiz os stus criados ao Collegio com roupa necessuria para se fazer car 'as suas Meninis. Collegio: poderi haver modifica gio a tespeito de familte do masmo Domingo ou dia Santo se recollhio ao comodo, o-saprir aos oito dias com roupa abertura do Collegio deveri ter principio no o outra alguma couza; para o que fará particulat ajuste. A Com este mez aeabia ter principio no primeiro de Jansiro de 181 .

devem ditigir-s: a L Loj de Paulo Martin, Fibo do segundo semestre do corrente anno, e darante elle, sejio remeitidas as Gazetss no proxims seguinte stmenta da Quitand $i$, as pessoas, que dezejarem que the: para a pronta entreza de cada huoxims seguinte stmestre. As providencias, que ultimamente se tem dado quaesquet, qua forem conducentes ás Numsros, se continuario na nova subscripḉo, e se daráo outras e Listas de daspachos, ficarío (como dasteşa do Publico. Todas as Gazetas Extraordinurias, ou Dohradis, com preferencu hum exemplar de dalivas pertencendo aos Subscriptores, a quen igualmente se remerters se faz a subseripcío para o novo gornal o Patrio que se haja de distribuir gratuitamente. Na mesma Loji

Sexta feira 18 do cotrente haverí Gazeta Extraordinaria, N. ${ }^{\circ}$ to.

$$
\text { RIO DE JANEIRO "A IMPRESSXO REGIA. } 1812 .
$$

(Fonte: Gazeta do Rio de Janeiro, 1812, No 101).

Particularmente, no caso das viúvas, essa situação era amenizada: ao terem que cuidar dos negócios do falecido marido, tinham suas vidas também voltadas à arena pública. Em fins de novembro de 1819, um caso intrigante aparecia nas páginas da Gazeta. D. Ana Barbosa de Miranda, testamentária de seu esposo falecido, com a ajuda de seu pai - o tenente coronel Antonio José da Costa Barbosa -, avisava a sociedade sobre a demolição das casas erguidas por Diogo Teixeira de Macedo nos terrenos de sua propriedade. $\mathrm{Na}$ publicação, informava a sentença da justiça a seu favor, que lhes julgou próprio o terreno, uma vez que ela sofria problemas com Teixeira, já que este queria vender as casas e mais benfeitorias (Gazeta do Rio de Janeiro, 1819, N 94).

A presença e participação das mulheres também começavam a ser alvo de comentários na sociedade. A peça $A$ mulher inimiga do seu sexo, encenada no Real Teatro em junho de 1817, em meio às manifestações públicas que congratulavam o fim da Revolução Pernambucana, teve contornos interessantes das mulheres que a assistiam. Segundo a descrição do redator da Gazeta, o espetáculo começava com o hino nacional cantado pelos músicos da casa que viram também nas senhoras a expressão de espectadoras e acompanhantes fiéis do hino, entoando-o sob vivas e lenços, fosse da plateia ou do camarote (Gazeta do Rio de Janeiro, 1817, $\mathrm{N}^{\circ} 3$ ).

As profundas transformações socioculturais ocorridas no Brasil durante permanência da Coroa Portuguesa teriam contornos importantes na formação de uma nova concepção do espaço público. As ações dos diferentes sujeitos históricos no universo da política demonstravam claramente que o tempo da subserviência colonial ficara para trás. 